later dates examined them microscopically. The trephine employed was $1.5 \mathrm{~mm}$. in diameter, and in all a peripheral iridectomy, leaving the sphincter untouched, was performed. The trephine hole was made well forward to avoid injury to the ciliary body. The intraocular pressure was always considerably lower after the operation, and remained so up to four months (the latest period at which the eyes were removed). A careful description of the microscopical anatomy of the eyes is given, and illustrated by three excellent plates. The most important point found in practically all the specimens, was that the ciliary body had been dragged forward, and was implicated in the scar. Clinically there was no evidence of this to be seen after careful examination. Colombo rightly points out that experiments on an eye such as that of the rabbit are not necessarily conclusive evidence that the same results happen in the human eye.

In the second part he discusses the clinical work of other authors, as well as the bearing of his experimental work on the results obtained. He notes that Meller, Sattler, Di Marzio, and Guglianetti had expressed surprise at finding an irido-ciliary entanglement in human eyes, in which they had no clinical evidence of its existénce. He points out that in Elliot's operation the conditions favour the involvement of uveal tissue in the wound owing to the long period during which the anterior chamber remains empty. Colombo holds the opinion that a so-called filtering cicatrix does not occur in the absence of uveal tissue. He sums up the question thus: "Such a fistula is in all probability formed by the presence of a more or less considerable involvement of uveal tissue, such involvement being also concerned with the irido-cyclitis that so commonly follows the operation. To the presence of such a fistula the late cases of deep infection are due."

Colombo says nothing about the tendency to early appearance of lens opacity in trephined eyes, but his theory has, if correct, something suggestive in this connection as well. In his view the ideal operation must get some involvement of uveal tissue which need only be minimal and invisible to ordinary clinical examination.

E. E. H.

\title{
INJURIES OF THE EYE FROM HIGH VOLTAGE CURRENTS
}

Morax, V. (Paris).-Lesions of iris, ciliary body, and lens consecutive to discharge of high voltage currents. Annal. d'Oculistique, Vol. CLV., July, I9I8. 
Since the beginning of 1918 Morax had had the opportunity of watching three cases which presented points of medico-legal importance in view of changes in the eyes coming on after, and attributed to, exposure to high voltage currents or fulguration or electrocution, as he calls it. Even if it is admitted that late lens opacification can succeed such exposure, it is not, on the other hand, established that an iritis or iridocyclitis precedes or accompanies these lens changes. In the first case, Morax was inclined to suppose the extensive skin burns had been the entrance point of organisms which had reached the iris and ciliary body through the circulation and so caused the trouble, but since the first case he has altered his views somewhat.

His first case, a man of 51 , on January 19,1918 , was working in a (step-down) transformer cage and had touched with the crown of his head a bar of the transformer carrying a triphase current of 12,000 volts, but exactly how it all happened no one can tell, for he merely recollects going into the cell and that, next day, he regained consciousness at the St. Louis Hospital. It was the arrest of the electric current in the factory which caused inquiry to be made, when the man was found unconscious with burns on vertex of head, wrists, and forearms. The man had had slight difficulty with vision beforehand but nothing more than would be accounted for by the four dioptres of hypermetropia present in each eye, $\mathrm{He}$ was kept in hospital for the burns, chiefly the scalp ones, and made no complaint of vision till February 16, when he spoke of difficulty in looking at the light, pains around left eye and a dimness of vision. The left eye showed iridocyclitis with "keratitis punctata," irregularity of pupil, and slight opacity of lens. One week later patient was transferred to the Eye Wards and atropin was begun: Right vision with $+3 \mathrm{D}$. sphere $=5 / 15$, Left vision with $+3 \mathrm{D}$. sphere $=5 / 35$; T.n.; deep scalp sloughs beginning to be shed off, other burns quite healed.

March 5.- Left eye better; transferred back.

April 10.- Seen again, this time for slight irritation and photophobia of right eye, cured with a few days of atropin.

May 31.-No irritative signs seen except with the corneal microscope, which showed some fine pigmented precipitates. Evident lens opacities in both, especially left. Vision in each eye as above. Tonometer $16 \mathrm{~mm}$. Hg. each.

May (? June) 16:- Scalp barely healed yet. Pupils dilate fully and circularly after atropin, slight ectropion uveae, but no pigment on lens capsule and no "K.P." Lens opacity remains diffuse, and incomplete, with oblique illumination it appears as specks with here and there greyer points; with transmitted light one sees a series of ill-defined opacities, which allow of a good fundus view, fundus normal; the opacities are greater in left eye. R.V. with 
+4D. sph. $=5 / 15 ;$ L.V. with $+5 \mathrm{D}$. sph. $=5 / 20$. Thus the left eye began to show signs of iridocyclitis on the 28th day after exposure to the current, this disappeared in 17 days, then less marked similar changes appeared at the third month in the right eye. The iridocyclitic changes disappeared but lens opacities remained.

The second case is that of a man of 44 who had worn glasses for the past 12 years for high hypermetropia but had never noticed any difference between the two eyes. On March 18, 1918, he proceeded to clean some conductors for a current of 15,000 volts, believing the current to be off ; a short circuit ensued and the man remembers nothing more. His fellow-workmen told him he lay unconscious for about 15 minutes. He had severe burns of right shoulder and left forearm-for these he attended the Lariboisiére as an-outpatient.

Towards the end of May he developed discomfort in left eye, some peri-ocular pains, conjunctival hyperaemia, and almost simultaneously marked dimness of vision. These irritative phenomena did not last more than four to five days. Right eye also affected but no hyperaemia nor painful phenomena. Vision quite dim; clears up after some days. It is not till June 10 that he sees Morax. Lightning diagnosis of "cataract secondary to old irido-cyclitis." This shows under how false an aspect the electro-traumatic manifestations can present themselves. With the loupe (right eye) cornea clear, no conjunctival redness; anterior surface of iris normal; pupil edge has a slightly irregular pigmented piping, forming a small clump at one point. Lens shows small cortical opacities as dots or specks, but transparence of lens is only slightly interfered with. Right vision with $+4 \mathrm{D}$. $\mathrm{sph} .=8 / 10$; tonometer $18 \mathrm{~mm}$. Hg. Deep parts of eye normal.

Left eye-cornea quite clear, complete cataract, edge of pupil slightly irregular with some synechiae and some ectropion uveae. On lens capsule a ring of pigmented dots is seen; no Rrecipitates. Tonometer $18 ; \mathrm{V} .=$ p. l., good projection. Urine healthy, Wassermann negative, forearm burn barely healed yet. Here iridocyclitis appeared two and a half months after the trauma and although not of long duration left traces.

Bistis's case had lens opacities starting one month after exposure, Terrien's three months, Bichelonne's seven months. This late change may be related to the tardy influence of the physical agent, for we know that the cutaneous lesions of the ultra-violet and the $\mathrm{X}$-rays and of radium do not come on under identical conditions; the incubation can be more or less long and we know, for example, that it is at least eighteen days for X-rays. Possibly the late lens opacification is analogous to the tardy falling off of the hair after exposure to X-rays, but Morax does not feel inclined to say whether the lesions are due to the electric current itself or to the action of 
the luminous rays which are always a marked feature of these short circuits.

Morax's conclusions are that after accidental electrocutions one can see supervene the signs of irido-ciliary inflammation preceding or accompanying the lens changes, the eyes being affected together or successively, the first signs being from ten days to three months after the accident. "The mere verification, or finding, of sequelae of iridocyclitis and of the lens lesions will not warrant the attribution of the ocular lesions to an endogenous infectious process." This, however, appears to be just the special difficulty of these two cases, notes of the third case not being given in the present paper.

W. C. Souter.

\section{BOOK NOTICES}

Ferraris' Dioptric Instruments, being an elementary exposition of Gauss' Theory and its Applications. Translated by OsCar Faber, D.Sci, O.B.E. Printed at the request of the Ministry of Munitions. Published by H.M. Stationery Office, 1919. Price 4s. net.

In 1840, Gauss published in the Royal Society of Göttingen, a paper entitled "Dioptric' Researches," tracing the path of the central rays of light through a homocentric system of refracting media. His method, which expounded the theory of cardinal or fundamental points, greatly simplified the theory of dioptric instruments. 'Previous researches fell into two groups-those in which the thickness of lenses was neglected and those in which it was not. The first group, in the hands of Coles, Euler, Lagrange, and others, led to simple formulae and graphic constructions. The second resulted in complicated formulae, little or not at all adapted to geometrical constructions. There was a natural tendency. therefore to neglect the thickness of lenses in cases where this procedure was unjustifiable. Gauss' theory permitted of equal simplicity and accuracy in all cases. Of the cardinal points the foci were previously known, and Möbius, in 1830, described the principal points, but Gauss first worked out in detail their properties. In 1845 , Listing did the same service for the nodal points, which had been previously noticed by Biot.

Carl Friedrich Gauss was one of the greatest mathematicians of his age, but he wrote in a difficult though precise and exhaustive style. Like most of his work, his theory of cardinal points remained buried and unknown to any but a few mathematicians, who had little interest in the practical applications. The analytical proof of 